\title{
Hyperinsulinemic hypoglycemia with nesidioblastosis: histologic features and growth factor expression
}

\author{
Kandelaria M Rumilla, Lori A Erickson, F John Service, Adrian Vella, \\ Geoffrey B Thompson, Clive S Grant and Ricardo V Lloyd \\ Division of Anatomic Pathology, Mayo Clinic, Rochester, MN, USA
}

\begin{abstract}
Hypoglycemia secondary to nesidioblastosis is rare in adults, and the pathogenesis of this condition is unknown. To determine factors leading to nesidioblastosis in adults, we analyzed 36 cases of nesidioblastosis including 27 cases of postgastric bypass nesidioblastosis and 9 cases of idiopathic nesidioblastosis in adults by immunohistochemistry using antibodies to insulin-like growth factor1, insulin-like growth factor2 (IGF2), insulin-like growth factor one receptor- $\alpha$ epidermal growth factor receptor, transforming growth factor- $\beta 1$ and 2 , and transforming growth factor- $\beta$ receptor type 3 . Fifty-two surgically excised pancreatic specimens from patients with benign exocrine tumors and no evidence of hypoglycemia were used as controls. There was increased IGF2, insulin-like growth factor receptor1 receptor- $\alpha$ and transforming growth factor- $\beta$ receptor 3 expression in islets from nesidioblastosis patients compared to controls. Peliosis-type vascular ectasia was more common in nesidioblastosis patients compared to controls. These findings suggest that increased production of growth factors and growth factor receptors may contribute to the development of nesidioblastosis in adults.
\end{abstract}

Modern Pathology (2009) 22, 239-245; doi:10.1038/modpathol.2008.169; published online 17 October 2008

Keywords: nesidioblastosis; gastric bypass; IGF2; IGF1R $\alpha$; TGF $\beta$ R3; peliosis

Gastric bypass surgery has become an established treatment for patients with morbid obesity. Obesity rates continue to increase in the United States, from 22.9 to $30.5 \%$ between $1988-1994$ and $1999-2000$, respectively. ${ }^{1,2}$ Around 10000 bariatric procedures were performed yearly in the early 1990s in the United States, whereas an estimated 103000 bariatric procedures were performed in $2003 .{ }^{1}$

In the past few years an increasing number of patients with severe hypoglycemia including neuroglycopenia as a result of endogenous hyperinsulinemia in the postgastric bypass setting have been reported. ${ }^{3-6}$ These patients present with severe hypoglycemic symptoms including visual disturbances, altered mental status, seizures, and loss of consciousness, often postprandially. Nesidioblastosis has been most widely recognized in infants. Only rare cases have been reported in adults. Postgastric bypass

Correspondence: Dr RV Lloyd, MD, PhD, Division of Anatomic Pathology, Mayo Clinic, 200 First Street S.W., Rochester, MN 55901, USA.

E-mail: lloyd.ricardo@mayo.edu

Received 9 July 2008; revised 11 September 2008; accepted 16 September 2008; published online 17 October 2008 patients with nesidioblastosis represent a new and growing population of cases in adults.

The pathogenesis of nesidioblastosis is unknown. Early histopathologic descriptions of histologic features of nesidioblastosis included enlarged islet size and number, increased periductular islets, and enlarged $\beta$-cell nuclei. The histologic features were first associated with severe hypoglycemia in infants. ${ }^{7-9}$ In recent years, a number of genes including SUR1, Kir6.2, GCK, GLUD1, and short-chain 3-hydroxyacyl CoA dehydrogenase have been identified in infantile nesidioblastosis. ${ }^{10-12}$ An association with Beckwith-Weideman syndrome has also been identified. ${ }^{13,14}$ These genetic mutations have only rarely been identified in adult cases. ${ }^{15,16}$ The lack of recognized mutations in most adult cases suggests that the pathogenesis of adult nesidioblastosis may be different from infantile nesidioblastosis.

Although the percentage of people with prior gastric bypass surgery who develop hyperinsulinemic hypoglycemia is presumed to be small, a better understanding of this syndrome is needed to develop objective diagnostic criteria, identify predictive markers, and determine alternate medical targets for treatment. Because specific growth factors have been shown to be significant in the regulation 
of insulin secretion, ${ }^{17}$ we examined specific growth factors and growth factor receptors by immunohistochemistry and in situ hybridization to determine if they have a role in the development of adult nesidioblastosis. We report overexpression of insulin-like growth factor2 (IGF2), insulin-like growth factor one receptor- $\alpha$ (IGF1R $\alpha$ ), and transforming growth factor receptor $\beta 3$ (TGFR $\beta 3$ ) in islets of nesidioblastosis patients compared to normal controls. Histological examination showed that peliosis-type vascular ectasia is a useful feature that can assist in the diagnosis.

\section{Materials and methods}

\section{Tissue}

Pancreatic tissue from 36 adult patients who underwent partial pancreatectomy for nesidioblastosis at Mayo Clinic, Rochester, MN, USA between 1994 and 2007 were selected. Institution Review Board permission was obtained for the study. Twenty-seven of the thirty-six patients (twenty-five women and two men) had previously had Roux-en-Y bariatric bypass surgery for medically complicated morbid obesity. Nine patients (three women, six men) with idiopathic adult onset nesidioblastosis and no history of gastric surgery were also identified. A subset of patients have been previously reported. ${ }^{3}$ The control group consisted of 52 adult patients who underwent partial pancreatic resection at Mayo Clinic between 1993 and 2007 for benign pancreatic lesions including serous cystadenoma, mucinous cystadenoma, microcystic cystadenoma, and benign mucinous tumor. Inclusion criteria also included absence of pancreatitis or fibrosis and at least 10 interpretable islets. No patient had hypoglycemic symptoms. Demographic data including gender, age and body mass index (BMI), both current and maximum (to reflect pre- and postgastric bypass surgery) were collected. Clinical laboratory tests including serum insulin, glucose, C-peptide, sulfonylureas, antiinsulin antibodies, and $72 \mathrm{~h}$ fasts, as well as imaging the pancreas, and selective arterial calcium stimulation were performed in clinical evaluation of the patients.

\section{Pathology}

Features used for histologic confirmation of nesidioblastosis included islet cell hypertrophy, increased nuclear size of islet cells, and ductularinsular complexes after insulin staining. The presence or absence of vascular ectasia within islets was also evaluated.

\section{Immunohistochemistry}

Immunohistochemistry was performed on paraffinembedded tissue with the following antibodies: insulin-like growth factor1 (IGF1; 1:100), IGF2 (1:100), and IGF1R $\alpha$ (1:50; Millipore, Temecula, CA, USA); epidermal growth factor receptor (EGFR; 1:500), transforming growth factor $\beta 1$ (TGF $\beta 1$; 1:500), and TGF $\beta 2$ (Santa Cruz Biotechnology Inc., Santa Cruz, CA, USA); and TFG $\beta$ R3 (1:250; Abcam Inc., Cambridge, MA, USA). Selected growth factors have been shown to be significant in insulin regulation or been implicated in the pathogenesis of abnormal insulin regulation, including both the insulin-like and TGF families. ${ }^{17}$ Positive controls consisted of pituitary tissues and negative controls consisted of substituting normal serum for the primary antibodies. Immunoreactivity was graded from 0 (negative), $1+$ (weakly positive), $2+$ (moderately positive), and $3+$ (strongly positive), based on the most intense staining present in the islet cells. Immunostaining was evaluated by two observers without knowledge of the specific diagnosis in the cases.

\section{In Situ Hybridization}

In situ hybridization was performed on a subset of the cases (eight postgastric bypass nesidioblastosis, four idiopathic nesidioblastosis, and seventeen controls) using an antisense oligonucleotide probe designed to target IGF2 mRNA. A sense probe was used as a negative control. Antisense IGF2-AS (314) sequence was: GGTCTCACTGGGGCGGTAAGCAGC AATGCA. Sense IGF2-SS(211) sequence was: GAGA CACCAATGGGAATCCCAATGGGGAAG; Molecular Biology Core, Mayo Clinic, Rochester, MN, USA. ${ }^{15}$ Staining within the islets was graded on a scale of $0-3$.

\section{Statistical Analyses}

Statistical analyses were performed using $\chi^{2}$ and Fisher's exact tests for analysis of histologic features. The immunohistochemical stains were compared between study groups using Wilcoxon rank-sum tests. All tests were two-sided.

\section{Results}

\section{Patients}

Clinical information collected on the nesidioblastosis and control cases included age, gender, maximum and most recent BMI, and follow-up (Table 1). The postgastric bypass nesidioblastosis group included a higher proportion of women (twentyfive women, two men) than the idiopathic nesidioblastosis cases (three women, six men). The controls were also predominantly women (40 women, 12 men). The average age of patients with nesidioblastosis was 45 years and for controls was 58 years. The recent average BMI was $25.7 \mathrm{~kg} / \mathrm{m}^{2}$ for the idiopathic nesidioblastosis cases, $28.9 \mathrm{~kg} / \mathrm{m}^{2}$ for the postgastric 
Table 1 Demographics information of postgastric bypass nesidioblastosis, idiopathic nesidioblastosis, and control cases

\begin{tabular}{lccc}
\hline & Postgastric bypass nesidioblastosis & Idiopathic nesidoblastosis & Controls \\
\hline Number of cases & 27 & 9 & 52 \\
Gender F:M (\%F) & $25: 2(93 \%)$ & $3: 6(33 \%)$ & 45 \\
Mean age (years) & 45 & 25.7 & $58.12(77 \%)$ \\
Current BMI $\left(\mathrm{kg} / \mathrm{m}^{2}\right)$ & 28.9 & 26.3 & 58 \\
Maximum BMI $\left(\mathrm{kg} / \mathrm{m}^{2}\right)$ & 47.0 & $34(2-74)$ & 30.1 \\
Follow-up mean (range; months) & $11(1-55)$ & $\mathrm{NA}$ & $33(1-141)$ \\
Time since bypass (months) & $54(17-264)$ & $\mathrm{NA}$ \\
\hline
\end{tabular}

BMI, body mass index; NA, data not available.

Table 2 Immunohistochemical analysis of IGF2, IGF1R $\alpha$, TGF $\beta$ R3

\begin{tabular}{lccc}
\hline & $\begin{array}{c}\text { Nesidioblastosis (postgastric bypass } \\
\text { and idiopathic) } \mathrm{N}=36 \text { mean (s.e.) }\end{array}$ & $\begin{array}{c}\text { Controls } \mathrm{N}=52 \\
\text { mean (s.e.) }\end{array}$ & $\begin{array}{c}\text { P-value comparing } \\
\text { nesidioblastosis versus controls }\end{array}$ \\
\hline IGF2 & $2.74(0.11)$ & $1.97(0.16)$ & $0.001^{*}$ \\
IGF1R $\alpha$ & $2.57(0.11)$ & $1.92(0.16)$ & $0.008^{*}$ \\
TGF $\beta$ R3 & $2.76(0.118)$ & $2.48(0.083)$ & $0.012^{*}$ \\
\hline
\end{tabular}

* Statistically significant $P$-value.

bypass nesidioblastosis group, and $29.2 \mathrm{~kg} / \mathrm{m}^{2}$ for controls. Maximum BMI levels were higher in the postgastric bypass group $47.0 \mathrm{~kg} / \mathrm{m}^{2}$ than the idiopathic nesidioblastosis group $26.3 \mathrm{~kg} / \mathrm{m}^{2}$ or the control group $30.1 \mathrm{~kg} / \mathrm{m}^{2}$. The time from gastric bypass to pancreatic resection in postgastric bypass patients averaged 54 months (range 17-264 months). Follow-up after pancreatic surgery ranged from 1 to 74 months for the nesidioblastosis patients. Of the nesidioblastosis patients who underwent pancreatic resection all 27 postgastric bypass patients are alive, but 8 had recurrent or ongoing mild symptoms. Three of the nine patients with idiopathic nesidioblastosis had recurrent symptoms, two of which necessitated completion pancreatectomy. We examined the severity of nesidioblastosis as related to the postgastric bypass period. Because of the overlap of mild, moderate, and severe nesidioblastosis cases with the postgastric bypass periods, a clearcut relationship between severity of nesidioblastosis and postgastric bypass period could not be demonstrated.

\section{Histologic Features}

The islet cells in the nesidioblastosis cases were hypertrophied and were more irregular in shape and size compared to control islets (Figures 1 and 2). Enlarged islet cell nuclei were more prominent in nesidioblastosis cases. Peliosis-type vascular ectasia of the islets was present in $50 \%$ of nesidioblastosis cases compared to $12 \%$ of control cases $(P=0.001)$ (Figure 2). There were no significant differences in ductulo-insular complexes between nesidioblastosis and control cases.

\section{Immunohistochemistry}

Expression of IGF2, IGF1R $\alpha$, and TGF $\beta$ R3 (Figures 1a-d) were significantly increased in pancreatic islets from nesidioblastosis cases compared to controls $(P=0.001,0.008$, and 0.012 , respectively; Table 2$)$. The evaluation of immunostaining intensity between the two observers was generally in good agreement. The negative control slides did not show any positive staining. IGF2 staining was predominantly cytoplasmic, whereas IGF1R $\alpha$ staining was mainly cell membrane. TGF $\beta$ R3 staining was predominantly cytoplasmic with focal cell membrane staining. When two groups of nesidioblastosis patients (postgastric bypass and idiopathic) were separately compared to controls, the statistically significantly differences remained for the idiopathic nesidioblastosis group with all three markers and for the postgastric bypass cases for IGF2 and IGF1R $\alpha$ (Table 3). When comparing idiopathic and postgastric bypass nesidioblastosis in the idiopathic nesidioblastosis cases only IGF2 showed significantly different expression levels $(P=0.024)$ IGF1, EGFR, TGF $\beta 1$, and TGF $\beta 2$ did not show significant differences between nesidioblastosis cases and controls.

\section{In Situ Hybridization}

In situ hybridization for IGF2 showed expression of IGF2 with the antisense probe, whereas the sense probe was negative, indicating expression of IGF2 mRNA in islet cells. Significant differences in the levels of IGF2 mRNA expression were not detected in the subset of cases examined, because of the relatively 

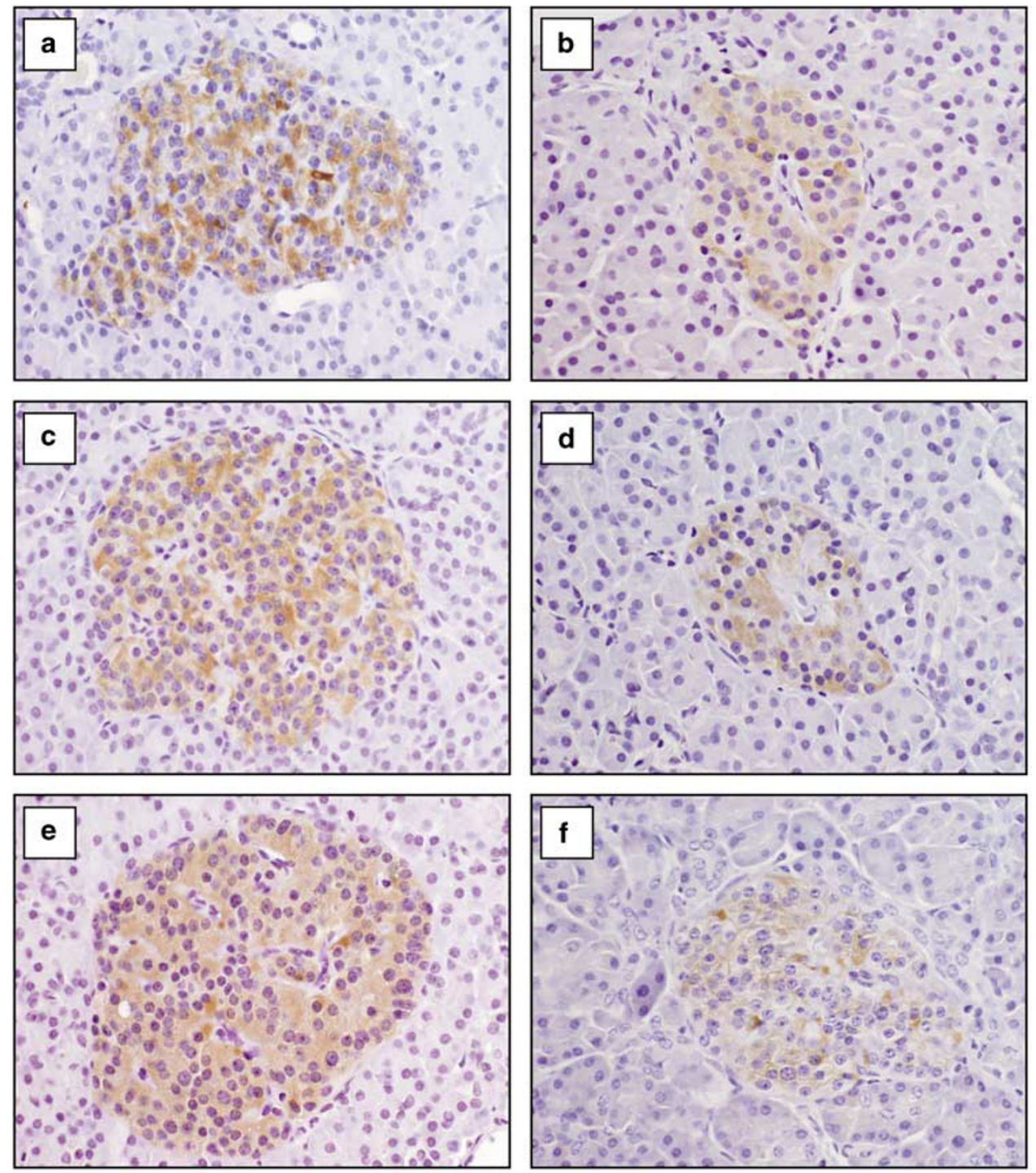

Figure 1 Immunohistochemical staining in islets from patients with nesidioblastosis (a, c, e), and control islets (b, d, f). (a) IGF2 staining shows $3+$ immunostaining in a postgastric bypass nesidioblastosis case. The islet is irregular with hypertrophied cells. There is moderate nuclear pleomorphism. (b) IGF2 is in a control islet showing $1+$ staining intensity. (c) IGF1R $\alpha$ showing a postgastric bypass nesidioblastosis case. The islet cells are hypertrophied, and there is $2+$ staining, which is predominantly cell membrane staining. (d) Control islet with $1+$ staining in a control case. (e) TGF $\beta$ R3 immunostaining in a postgastric bypass islet showing $2+$ staining in the hypertrophied islet cells. The staining is predominantly cytoplasmic with focal cell membrane staining. (f) Control islet showing weaker $1+$ staining for TGF $\beta$ R3. The staining is predominantly cytoplasmic with focal cell membrane staining.

weaker positive signal detected by ISH compared to that by immunohistochemistry (data not shown).

\section{Discussion}

The pathogenesis of nesidioblastosis in adults is unknown. This study shows increased expression of IGF2, IGF1R $\alpha$, and TGF $\beta$ R3 in pancreatic islets from patients with nesidioblastosis compared to controls. This finding suggests that certain growth factors and growth factor receptors contribute to the development of nesidioblastosis. Increased expression of IGF2 was identified in the idiopathic nesidioblas- tosis group compared to postgastric bypass group suggesting that the mechanisms and pathways involved in the pathogenesis of nesidioblastosis may vary with specific types of nesidioblastosis. These finding are not surprising, because the patients have similar symptoms resulting from hyperinsulinemia and hypoglycemia, but they also have distinct clinical and surgical histories.

Various growth factors and growth factor receptors have been shown to be important for insulin regulation. ${ }^{18}$ At least one member of the IGF family, IGF2, is associated with nonhyperinsulinemic hypoglycemia leading to paraneoplastic syndrome secondary to ectopic tumor production. ${ }^{19-27}$ In this 
study, IGF2 was present mainly in the cytoplasm of islet cells, whereas IGF1R $\alpha$ was predominantly cell membrane associated. This observation would suggest an effect of IGF1R $\alpha$ at the cell membrane to stimulate downstream effects, whereas IGF2 was probably functioning in the cytoplasm of the islet cells. IGF2 has also been reported with human overgrowth syndromes including Beckwith-Wiedeman syndrome, which has also been associated with nesidioblastosis. ${ }^{13,28-30}$ Studies in mice and transgenic mouse models has shown that the family of IGFs and IGF-binding proteins are involved in cellular functions including insulin and glucose regulation. ${ }^{31}$ Direct evidence of the role of IGF2 and IGF-binding proteins on proliferation of insulinproducing cells has been reported in mice with disruption of the MEN1 gene. ${ }^{32}$ In this model, there was overexpression of IGF2- and IGF-binding proteins $^{32}$ leading to $\beta$-cell proliferation and development of insulinomas. EGFR and several members of the TGF $\beta$ family (TGF $\beta 1$, TGF $\beta 2$, and TGF $\beta$ R3) are involved in a wide range of normal and neoplastic pathways, which may interact with the IGF family. ${ }^{33}$

Previous studies of pancreatic tissue with nesidioblastosis from Mayo Clinic showed that the islets had larger mean diameter $(214 \pm 7.7 \mu \mathrm{m})$ compared

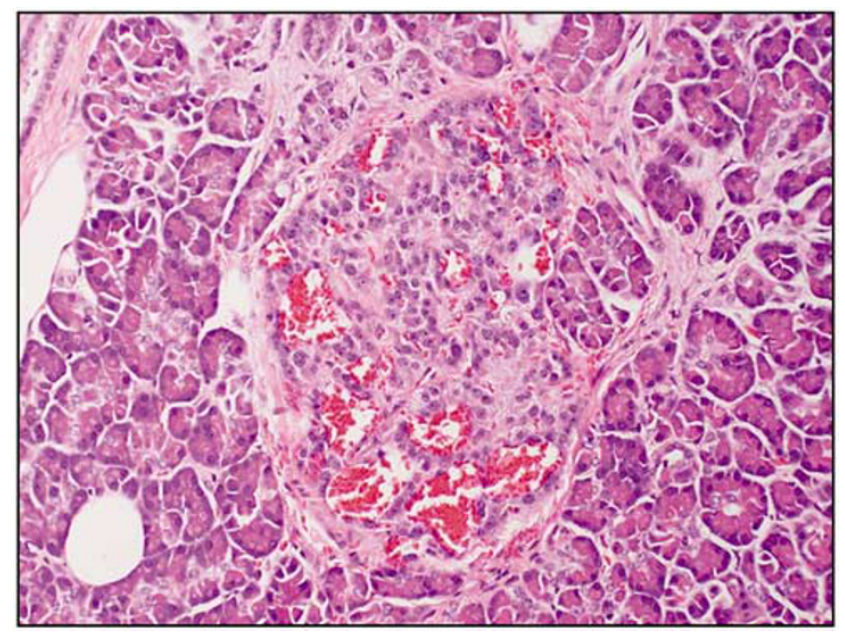

Figure 2 Islet with prominent dilated capillaries, which is associated with peliosis-like vascular ectasia. This finding was more common in islets from patients with nesidioblastosis compared to control islets. $\mathrm{H} \& \mathrm{E} \times 200$. to control cases $(151 \pm 7.3 \mu \mathrm{m})$, a finding confirmed by subsequent reports. ${ }^{34,35}$ One study, which utilized cadaveric pancreas as controls rather than the surgically resected pancreatic tissues did not find increased islet diameters in nesidioblastosis cases compared to controls. ${ }^{36}$ This study did, however, find significant differences in nuclear diameter of islet cells in nesidioblastosis compared to controls, ${ }^{36}$ which has been reported in other studies, as well. ${ }^{35}$ Peliosis-like vascular ectasia has previously been described in association with nesidioblastosis in several case reports of patients with other endocrinopathies including Von Hippel-Lindau and multiple endocrine neoplasia type I. $^{37-39}$ In the current study, peliosis-like vascular ectasia was more common in nesidioblastosis than in control cases. The peliosis-like vascular ectasia that was identified in the nesidioblastosis cases also tended to be more diffuse compared to control cases. The mechanism of peliosis-type vascular ectasia development is uncertain. ${ }^{40}$ It is possible that as different growth factors such as vascular endothelial growth factor (VEGF) and VEGFR may stimulate peliosis. ${ }^{41} \mathrm{~A}$ recent study reported that peliosis of the spleen was associated with massively elevated levels of VEGF. ${ }^{41}$ The practical implication of this observation is that the presence of peliosis-type vascular ectasia should raise the possibility of nesidioblastosis in pancreatic islets from adult patients with hypoglycemia who do not have an insulin-producing pancreatic endocrine tumor.

Some investigators have proposed that hypoglycemia is a component of late dumping syndrome, which is characterized by diaphoresis, weakness, dizziness, flushing, and palpitations with rare instances of hypoglycemia with severe neurologic symptoms or loss of consciousness. The symptoms in dumping syndrome are often amenable to dietary modification or medical management with octreotide and acarbose ${ }^{39}$ rather than necessitating surgical intervention. ${ }^{42}$

Long-term complications are increasingly important as the frequency of postgastric bypass for the treatment of morbid obesity increases. ${ }^{43}$ Definitive treatment of postgastric bypass and idiopathic adult nesidioblastosis includes gradient-guided pancreatectomy to decrease the source of endogenous excess insulin production. Hypotheses regarding the un-

Table 3 Comparing subtypes of nesidioblastosis (postgastric bypass and idiopathic) with control patients

\begin{tabular}{|c|c|c|c|c|c|}
\hline & $\begin{array}{c}\text { Postgastric bypass } \\
\text { nesidioblastosis } \mathrm{N}=27 \\
\text { mean (s.e.) }\end{array}$ & $\begin{array}{c}\text { Idiopathic } \\
\text { nesidioblastosis } \\
\mathrm{N}=9 \text { mean (s.e.) }\end{array}$ & $\begin{array}{c}\text { Controls } \mathrm{N}=52 \\
\text { mean (s.e.) }\end{array}$ & $\begin{array}{c}\text { P-value comparing } \\
\text { postgastric bypass nesidioblastosis } \\
\text { versus controls }\end{array}$ & $\begin{array}{c}\text { P-value comparing } \\
\text { idiopathic } \\
\text { nesidioblastosis } \\
\text { versus controls }\end{array}$ \\
\hline IGF2 & $2.62(0.12)$ & $3.11(0.18)$ & $1.97(0.16)$ & $0.007^{*}$ & 0.001 * \\
\hline IGF1R $\alpha$ & $2.46(0.4)$ & $2.89(0.14)$ & $1.92(0.16)$ & $0.049^{*}$ & $0.015^{*}$ \\
\hline TGF $\beta$ R 3 & $2.71(0.115)$ & $2.89(0.111)$ & $2.48(0.083)$ & 0.054 & $0.040^{*}$ \\
\hline
\end{tabular}

*Statistically significant $P$-value. 
derlying mechanism of postgastric bypass nesidioblastosis include adaptive $\beta$-cell hypertrophy that develops during obesity, which does not regress; a severe manifestation of dumping syndrome; a previously unrecognized hyperinsulinemia syndrome or underlying growth factor abnormality, which becomes apparent after bypass surgery; or an effect of altered anatomic structures secondary to the surgical intervention disrupts normal signaling pathways that is not correctly reestablished as the patient returns to normal or near normal weight. The pathophysiology of this process likely involves multiple mechanisms. Glucagon-like peptide1 has been proposed as a possible causative mechanism of nesidioblastosis because of its effects on islet cell neogenesis and $\beta$-cell apoptosis leading to islet cell hyperplasia in rodents. ${ }^{44}$ Weight loss after gastric bypass in severely obese patients might unmask a $\beta$-cell defect that promotes hyperinsulism and islet cell hyperplasia. ${ }^{3,44}$

We observed a higher prevalence of women patients with postgastric bypass nesidioblastosis, which most likely reflects the women predominance among individuals who have undergone gastric bypass for morbid obesity. ${ }^{45,46}$

In summary, IGF2, IGF1R $\alpha$, and TGF $\beta$ R3 are overexpressed pancreatic tissues from patients with nesidioblastosis. We have observed that peliosis-like vascular ectasia is increased in nesidioblastosis. Much remains to be learned to elucidate the pathophysiology of this disorder and develop more efficacious and less invasive treatment modalities.

\section{Acknowledgement}

We thank Shuya Zhang for her technical support in preparation of the immunohistochemical slides and in situ hybridization.

\section{Disclosure/conflict of interest}

No relevant financial or other disclosures or conflicts of interest.

\section{References}

1 Steinbrook R. Surgery for severe obesity. N Engl J Med 2004;350:1075-1079.

2 Flegal KM, Carroll MD, Ogden CL, Johnson CL. Prevalence and trends in obesity among US adults, 1999-2000. JAMA 2002;288:1723-1727.

3 Service GJ, Thompson GB, Service FJ, et al. Hyperinsulinemic hypoglycemia with nesidioblastosis after gastric-bypass surgery. N Engl J Med 2005;353: 249-254.

4 Patti ME, McMahon G, Mun EC, et al. Severe hypoglycaemia post-gastric bypass requiring partial pancreatectomy: evidence for inappropriate insulin secretion and pancreatic islet hyperplasia. (see comment). Diabetologia 2005;48:2236-2240.

5 Eden Engstrom B, Burman P, Holdstock C, et al. Effects of gastric bypass on the GH/IGF-I axis in severe obesity-and a comparison with GH deficiency. Eur J of Endocrinol 2006;154:53-59.

6 Carpenter T, Trautmann ME, Baron AD. Hyperinsulinemic hypoglycemia with nesidioblastosis after gastric-bypass surgery. $\mathrm{N}$ Engl J Med 2005;353: 2192-2194.

7 Brown RE, Young RB. A possible role for the exocrine pancreas in the pathogenesis of neonatal leucinesensitive hypoglycemia. Am J of Dig Dis 1970;15: 65-72.

8 Yakovac WC, Baker L, Hummeler K. Beta cell nesidioblastosis in idiopathic hypoglycemia of infancy. J Pediatr 1971;79:226-231.

9 Aynsley-Green A, Polak JM, Bloom SR, et al. Nesidioblastosis of the pancreas: definition of the syndrome and the management of the severe neonatal hyperinsulinaemic hypoglycaemia. Arch Dis Child 1981;56: 496-508.

10 Fournet JC, Verkarre V, De Lonlay P, et al. Loss of imprinted genes and paternal SUR1 mutations lead to hyperinsulinism in focal adenomatous hyperplasia. Ann Endocrinol 1998;59:485-491.

11 Greer RM, Shah J, Jeske YW, et al. Genotypephenotype associations in patients with severe hyperinsulinism of infancy. Pediatr Dev Pathol 2007;10: 25-34.

12 Reinecke-Luthge A, Koschoreck F, Kloppel G. The molecular basis of persistent hyperinsulinemic hypoglycemia of infancy and its pathologic substrates. Virchows Arch 2000;436:1-5.

13 Fukuzawa R, Umezawa A, Morikawa Y, et al. Nesidioblastosis and mixed hamartoma of the liver in Beckwith-Wiedemann syndrome: case study including analysis of H19 methylation and insulin-like growth factor 2 genotyping and imprinting. Pediatr Dev Pathol 2001;4:381-390.

14 Kaczirek K, Niederle B. Nesidioblastosis: an old term and a new understanding. World J Surg 2004;28:12271230.

15 Service FJ, Natt N, Thompson GB, et al. Noninsulinoma pancreatogenous hypoglycemia: a novel syndrome of hyperinsulinemic hypoglycemia in adults independent of mutations in Kir6.2 and SUR1 genes (see comment). J Clin Endocrinol Metab 1999; 84:1582-1589.

16 Glaser B, Kesavan P, Heyman M, et al. Familial hyperinsulinism caused by an activating glucokinase mutation. N Engl J Med 1998;338:226-230.

17 Lloyd R, Erickson L, Nascimento A, Kloppel G. Neoplasms causing nonhyperinsulinemic hypoglycemia. Endocr Pathol 1999;10:291-297.

18 Rhodes CJ, White MF. Molecular insights into insulin action and secretion. Eur J Clin Invest 2002;32(Suppl 3):3-13.

19 Beckers MM, Slee PH, van Doorn J. Hypoglycaemia in a patient with a gastrointestinal stromal tumour. Clin Endocrinol 2003;59:402-404.

20 Berman J, Harland S. Hypoglycaemia caused by secretion of insulin-like growth factor 2 in a primary renal cell carcinoma. Clin Oncol ( $\mathrm{R}$ Coll Radiol) 2001;13:367-369.

21 Bujanda DA, Vera JC, Suarez MA, et al. Hypoglycemic coma secondary to big insulin-like growth factor II 
secretion by a giant phyllodes tumor of the breast. Breast J 2007;13:189-191.

22 Daughaday WH. Hypoglycemia due to paraneoplastic secretion of insulin-like growth factor-I. J Clin Endocrinol Metab 2007;92:1616.

23 de Boer J, Jager PL, Wiggers T, et al. The therapeutic challenge of a nonresectable solitary fibrous tumor in a hypoglycemic patient. Int J Clin Oncol 2006;11:478-481.

24 Fernando HS, Hawkyard SJ, Poon P, Musa M. Renal cell carcinoma with non-islet cell tumor hypoglycemia. Int J Urol 2006;13:985-986.

25 Kameyama K, Okumura N, Kokado Y, et al. Solitary fibrous tumor associated with non-islet cell tumor hypoglycemia. Ann Thorac Surg 2007;84:292-294.

26 Sato R, Tsujino M, Nishida K, et al. High molecular weight form insulin-like growth factor II-producing mesenteric sarcoma causing hypoglycemia. Intern Med 2004;43:967-971.

27 Wakami K, Tateyama H, Kawashima H, et al. Solitary fibrous tumor of the uterus producing high-molecularweight insulin-like growth factor II and associated with hypoglycemia. Int J Gynecol Pathol 2005;24: 79-84.

28 Fournet JC, Mayaud C, de Lonlay P, et al. Unbalanced expression of $11 p 15$ imprinted genes in focal forms of congenital hyperinsulinism: association with a reduction to homozygosity of a mutation in ABCC8 or KCNJ11. Am J Pathol 2001;158:2177-2184.

29 de Lonlay P, Fournet J-C, Rahier J, et al. Somatic deletion of the imprinted $11 \mathrm{p} 15$ region in sporadic persistent hyperinsulinemic hypoglycemia of infancy is specific of focal adenomatous hyperplasia and endorses partial pancreatectomy. J Clin Invest 1997; 100:802-807.

30 Best LG, Gilbert-Barness E, Gerrard DE, GendronFitzpatrick A, Opitz JM. 'Double-muscle' trait in cattle: a possible model for Wiedemann-Beckwith syndrome. Fetal Pediat Pathol 2006;25:9-20.

31 Silha JV, Murphy LJ. Insights from insulin-like growth factor binding protein transgenic mice. Endocrinology 2002;143:3711-3714.

32 Fontaniér S, Tost J, Wierinckx A, et al. Gene expression profiling in insulinomas of Men1 beta-cell mutant mice reveals early genetic and epigenetic events involved in pancreatic beta-cell tumorigenesis. Endocr Relat Cancer 2006;13:1223-1236.

33 Daughaday WH, Deuel TF. Tumor secretion of growth factors. Endocrinol Metab Clin North Am 1991;20:539-563.
34 Thompson GB, Service FJ, Andrews JC, et al. Noninsulinoma pancreatogenous hypoglycemia syndrome: an update in 10 surgically treated patients. Surgery 2000;128:937-944.

35 Anlauf M, Wieben D, Perren A, et al. Persistent hyperinsulinemic hypoglycemia in 15 adults with diffuse nesidioblastosis: diagnostic criteria, incidence, and characterization of beta-cell changes. Am J Surg Pathol 2005;29:524-533.

36 Meier JJ, Butler AE, Galasso R, Butler PC. Hyperinsulinemic hypoglycemia after gastric bypass surgery is not accompanied by islet hyperplasia or increased beta-cell turnover. Diabetes Care 2006;29:1554-1559.

37 Kovacs K, Horvath E, Asa SL, et al. Microscopic peliosis of pancreatic islets in a woman with MEN-1 syndrome. Arch Pathol Lab Med 1986;110:607-610.

38 Chetty R, Kennedy M, Ezzat S, Asa SL. Pancreatic endocrine pathology in von Hippel-Lindau disease: an expanding spectrum of lesions. Endocr Pathol 2004;15:141-148.

39 Pernicone PJ, Lie JT. Isolated peliosis of pancreatic islet cell adenoma. Arch Pathol Lab Med 1987;111: 690-691.

40 Carvajal SH, Mulvihill SJ. Postgastrectomy syndromes: dumping and diarrhea. Gastroenterol Clin North Am 1994;23:261-279.

41 Joseph F, Younis N, Haydon G, et al. Peliosis of the spleen with massive recurrent hemorrhagic ascites, despite splenectomy, and associated with elevated levels of vascular endothelial growth factor. Eur J Gastroenterol Hepatol 2004;16:140-146. Review.

42 Imhof A, Schneemann M, Schaffner A, Brandle M. Reactive hypoglycemia due to late dumping syndrome: successful treatment with acarbose. Swiss Med Wkly 2001;131:81-83.

43 Abell TL, Minocha A. Gastrointestinal complications of bariatric surgery: diagnosis and therapy. Am J Med Sci 2006;331:214-218.

44 Klöpell G, Anlauf M, Raffel A, Perren A, Knoefel WT. Adult diffuse nesidioblastosis: genetically or environmentally induced? Hum Pathol 2008;39:3-8 Review.

45 Livingston EHMD, Huerta SMD, Arthur DRNMHA, et al. Male gender is a predictor of morbidity and age a predictor of mortality for patients undergoing gastric bypass surgery. Ann Surg 2002;236:576-582.

46 Tymitz K, Kerlakian G, Engel A, Bollmer C. Gender differences in early outcomes following hand-assisted laparoscopic Roux-en-Y gastric bypass surgery: gender differences in bariatric surgery. Obes Surg 2007; 17:1588-1591. 